\title{
Scapular winging: anatomical review, diagnosis, and treatments
}

\author{
Ryan M. Martin · David E. Fish
}

Published online: 2 November 2007

(C) Humana Press 2007

\begin{abstract}
Scapular winging is a rare debilitating condition that leads to limited functional activity of the upper extremity. It is the result of numerous causes, including traumatic, iatrogenic, and idiopathic processes that most often result in nerve injury and paralysis of either the serratus anterior, trapezius, or rhomboid muscles. Diagnosis is easily made upon visible inspection of the scapula, with serratus anterior paralysis resulting in medial winging of the scapula. This is in contrast to the lateral winging generated by trapezius and rhomboid paralysis. Most cases of serratus anterior paralysis spontaneously resolve within 24 months, while conservative treatment of trapezius paralysis is less effective. A conservative course of treatment is usually followed for rhomboid paralysis. To allow time for spontaneous recovery, a 6-24 month course of conservative treatment is often recommended, after which if there is no recovery, patients become candidates for corrective surgery.
\end{abstract}

Keywords Scapular winging - Serratus anterior .

Trapezius $\cdot$ Rhomboid $\cdot$ Long thoracic nerve

\section{Introduction}

Scapular winging is a rare, but potentially debilitating condition that can affect the ability to lift, pull, and push heavy objects, as well as to perform daily activities of

R. M. Martin · D. E. Fish ( $\varangle)$

Department of Orthopaedics, Physical Medicine and

Rehabilitation, David Geffen School of Medicine at UCLA, 1250, 16th St, 7th Floor, Tower Bld, Rm 745, Santa Monica, CA 90404, USA

e-mail: dfish@mednet.ucla.edu living, such as brushing one's hair and teeth and carrying grocery bags [1]. Cosmetically, some patients may be distressed by pronounced winging [2]. Disrupting scapulohumeral rhythm, scapular winging contributes to loss of power and limited flexion and abduction of the upper extremity and can be a source of considerable pain [3-8]. A condition due to a number of etiologies, most cases are due to lesions of the long thoracic and spinal accessory nerves that innervate the serratus anterior and trapezius muscles, respectively. Rarely, it may also be due to a lesion to the dorsal scapular nerve that innervates the rhomboid muscles. These scapular muscles (Fig. 1) contribute to keeping the medial border of the scapula protracted against the posterior thoracic wall, and denervation or paralysis of any of these muscles results in the winging of the medial border of the scapula as it lifts off the thoracic wall. In addition, the scapula may translate medially or laterally along the posterior thoracic wall due to unopposed muscle contraction of the other functioning scapular muscles, a distinction known as medial (serratus anterior paralysis) or lateral (trapezius or rhomboid paralysis) winging (Table 1). Scapular winging may present in a variety of clinical contexts, and may be due to traumatic- or sports-related injury [2, 4, 5, 8-22], iatrogenic injury $[1,2,12,15,16,19$, 23-27], or spontaneous in nature [6-8, 11, 27-30]. Here we discuss incidence and demographics, pertinent anatomy, the nature of the injury, diagnostic tests, and treatment options for scapular winging due to serratus anterior, trapezius, and rhomboid muscle paralysis.

\section{Incidence/Demographics}

Scapular winging due to serratus anterior palsy is a rare lesion. Fardin et al. [29] reported an incidence of 15 cases 
Fig. 1 Anatomical relationship of the serratus anterior, trapezius, and rhomboid muscles around the scapula, with the rhomboids just deep to the trapezius. Modified from Ref. [44, p. 52, Fig. 2.43]

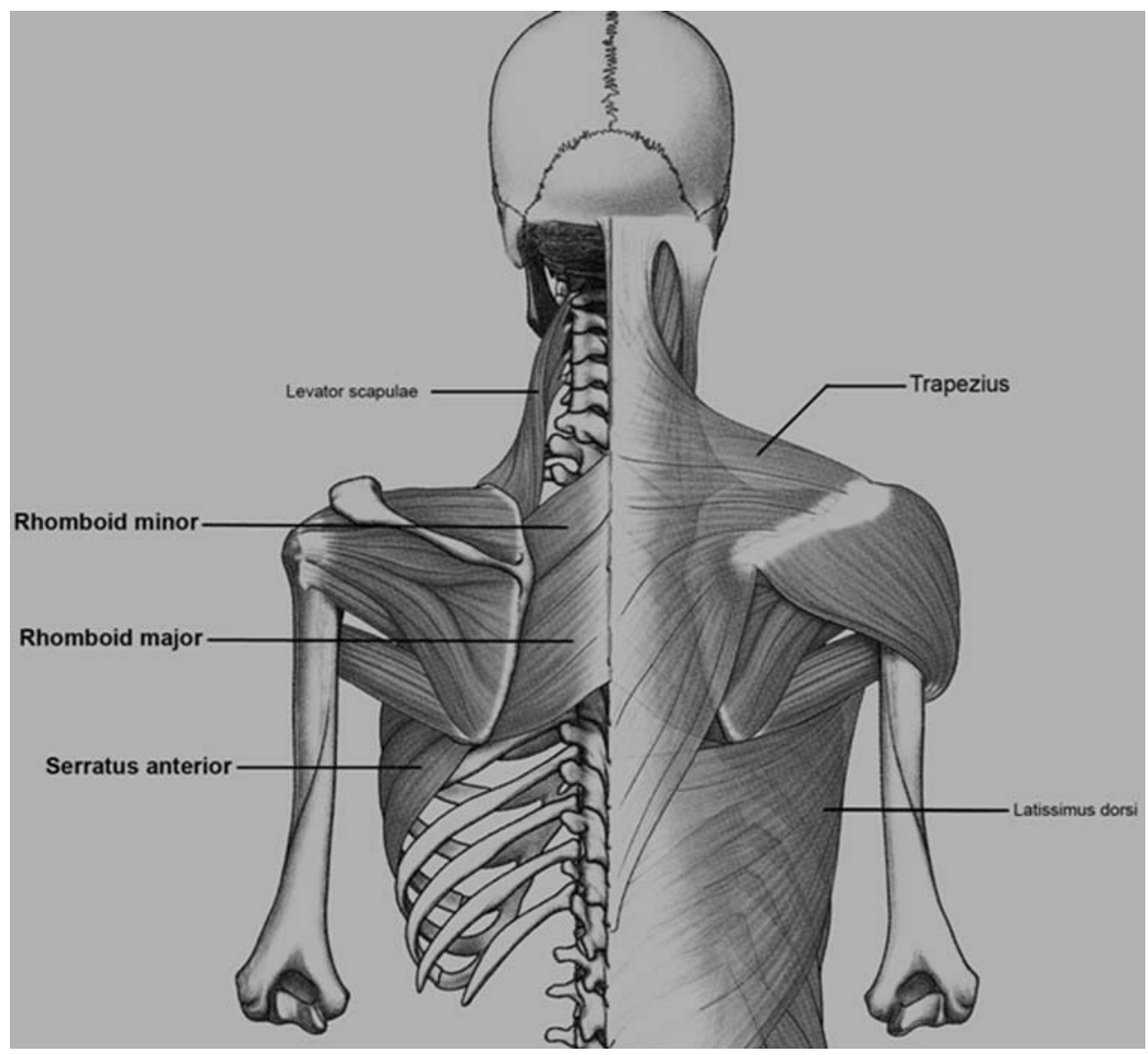

Table 1 Neurogenic causes of scapular winging and the physical exam

\begin{tabular}{|c|c|c|c|}
\hline & Medial winging & Lateral winging & \\
\hline Injured nerve & Long thoracic & Spinal accessory & Dorsal scapular \\
\hline Muscle palsy & Serratus anterior & Trapezius & Rhomboids \\
\hline Physical exam & $\begin{array}{l}\text { Arm flexion; push-up } \\
\text { motion against a wall }\end{array}$ & $\begin{array}{l}\text { Arm abduction; external } \\
\text { rotation against resistance }\end{array}$ & $\begin{array}{l}\text { Arm extension from } \\
\text { full flexion }\end{array}$ \\
\hline $\begin{array}{l}\text { Position of the scapula } \\
\text { compared to normal }\end{array}$ & $\begin{array}{l}\text { Entire scapula displaced more } \\
\text { medial and superior }\end{array}$ & $\begin{array}{l}\text { Superior angle more } \\
\text { laterally displaced }\end{array}$ & $\begin{array}{l}\text { Inferior angle more laterally } \\
\text { displaced }\end{array}$ \\
\hline
\end{tabular}

in 7,000 patients seen in their electromyographical laboratory. Overpeck and Ghormley [31] found only one case of serratus anterior paralysis in 38,500 patients observed at the Mayo Clinic, while Remak [32] diagnosed three cases of serratus anterior paralysis in a series of 12,000 neurological examinations. Gregg et al. [4] claims serratus anterior paralysis to be a "fairly common entity," observing 10 cases in 3 years amongst the practice of 20 orthopedists in the University of Pennsylvania hospital system, although no rate of incidence could be established as the total number of patients examined was not reported. Incidence of scapular winging due to trapezius paralysis is rare and difficult to assess. Awareness of the possibility of iatrogenic injury to the spinal accessory nerve during neck surgery has led to newer techniques that have reduced the incidence of trapezius palsy since its peak in the 1950s [7]. There are no published reports in the English language literature stating the incidence of scapular winging due to rhomboid paralysis. Indeed, there are only anecdotal statements describing rhomboid paralysis as rare and its functional effects as even rarer [33, 34].

Paralysis of the serratus anterior muscle has been well documented amongst professional and amateur athletes of a variety of sports, including archery, ballet, baseball, basketball, body building/weight lifting, bowling, football, golf, gymnastics, hockey, soccer, tennis, and wrestling [4, $6,11,13,28,35,36]$. Athletic injuries have also been attributable to trapezius [7, 37] and rhomboid paralysis [20, 
21, 38, 39]. Occupational injuries causing serratus anterior paralysis have been reported in the literature in individuals working as car mechanics, navy airmen, scaffolders, welders, carpenters, laborers, and a seamstress [11, 40-43].

\section{Pertinent anatomy and biomechanics}

\section{Serratus anterior}

The serratus anterior is a broad flattened sheet of muscle originating from the first nine ribs and passes posteriorly around the thoracic wall before inserting into the costal surface of the medial border of the scapula [44]. The serratus anterior has three functional components $[4,8]$. The superior component originates from the first and second ribs and inserts into the superior medial angle of the scapula [4, 8]. This component serves as the anchor that allows the scapula to rotate when the arm is lifted overhead [4]. The middle component of the serratus anterior originates from the third, fourth, and fifth ribs and inserts on the vertebral border of the scapula, serving to protract the scapula $[4,8]$. The inferior component originates from the sixth to ninth ribs and inserts on the inferior angle of the scapula $[4,8]$. This third portion serves to protract the scapula and rotate the inferior angle upward and laterally [4]. As a whole, the main function of the serratus anterior is to protract and rotate the scapula, keeping it closely opposed to the thoracic wall and optimizing the position of the glenoid for maximum efficiency for upper extremity motion $[4,8,44]$.

The serratus anterior is solely innervated by the long thoracic nerve, originating from the anterior rami of the fifth, sixth, and seventh cervical nerves [4, 8, 44]. Branches from the fifth and sixth cervical nerves pass anteriorly through the scalenus medius muscle before joining the seventh cervical nerve branch that coursed anteriorly to the scalenus medius $[4,8,45]$. The long thoracic nerve then dives deep to the brachial plexus and the clavicle to pass over the first rib [4, 8]. Here, the nerve enters a fascial sheath $[45,46]$ and continues to descend along the lateral aspect of the thoracic wall to innervate the serratus anterior muscle (Fig. 2) [4, 8]. An average of $24 \mathrm{~cm}$ in length [27], it is this long and winding course that is postulated to make the nerve susceptible to mechanical injury.

\section{Trapezius}

The trapezius muscle, like the serratus anterior, serves to elevate, retract, and rotate the scapula [7]. The muscle originates from the skull and the spinous processes of the first cervical vertebra through the 12th thoracic vertebra

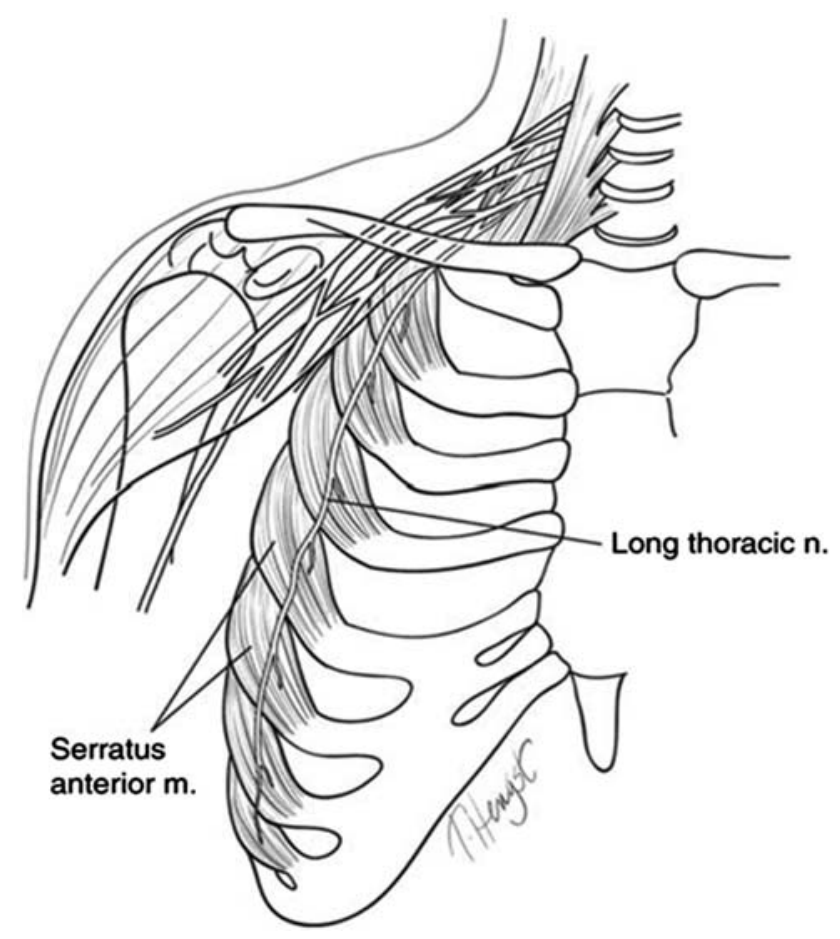

Fig. 2 Course of the long thoracic nerve to its innervations of the serratus anterior muscle. Proposed vulnerable sites for injury include compression of the nerve between the clavicle and first rib and traction within the nerve's fascial sheath [72, Fig. 1]

[7, 44]. The primary insertion is along the spine of the scapula [7, 44]. Separated into three components, the superior portion elevates the scapula and rotates the lateral angle upwardly, the middle portion adducts and retracts, and the inferior portion depresses the scapula and rotates the inferior angle laterally [7, 12]. The trapezius is solely innervated by the spinal accessory nerve, or cranial nerve $\mathrm{XI}$, which crosses the posterior cervical triangle superficially before diving vertically along the deep surface of the trapezius [7, 44].

\section{Rhomboids}

Just deep to the trapezius, the two rhomboid muscles work together to retract and elevate the scapula and rotate its lateral border downward [5, 22, 44, 47, 48]. The smaller rhomboid minor is a cyndrical muscle that finds its origin in the ligamentum nuchae of the neck and the spinous processes of the seventh cervical and first thoracic vertebrae $[44,47]$. It projects downward and laterally to the medial border of the scapula at the base of the scapular spine [44, 47]. The larger and more inferior rhomboid major originates from the spinous processes of the second through fifth thoracic vertebrae and inserts on the medial border of the scapula, from the insertion of the rhomboid 
minor to the inferior angle of the scapula [44, 47]. Both rhomboid muscles are innervated by the dorsal scapular nerve, with its fibers predominantly derived from the C5 nerve root with minor contributions from $\mathrm{C} 4$ or $\mathrm{C} 6$ [22, 44, $49,50]$. Like some of the fibers of the long thoracic nerve, the dorsal scapular nerve penetrates the scalenus medius muscle, before heading to the levator scapulae, giving off innervating fibers to the muscle $[44,49]$. The nerve then may pass deep to or pierce the levator scapulae muscle before diving under the brachial plexus and running to the anterior surface of the rhomboid muscles [22, 34, 44, 49].

\section{Etiology}

Serratus anterior palsy

The commonest cause of scapular winging is serratus anterior paralysis, a dysfunction attributed to traumatic [2, 4, 8, 9, 11], non-traumatic [6, 8, 11, 28, 41, 51-53], and idiopathic $[6,8,11,28-30]$ lesions of the long thoracic nerve. Reported causes of non-traumatic injury to the long thoracic nerve include viral illness (influenza [11]; tonsillitis-bronchitis [6, 28]; poliomyelitis [6]), allergic-drug reactions [28], drug overdose [11], toxic exposure (herbicides and tetanus antitoxin [28]), muscular dystrophy-fascioscapulohumeral dystrophy [41, 5456], C7 radiculopathy [52], and aortic coarctation [6].

Most trauma-induced long thoracic nerve injury are neurapraxias as a result of blunt trauma $[4,8,9,11]$, such as sudden depression of the shoulder girdle [9] or unusual twisting of the neck and shoulder [4]. Trauma may also be due to repetitive movements, as seen in athletics $[4,13]$ and house-hold activities such as hedge-clipping [11], digging [11], car washing [57], or prolonged lying in bed with the arms abducted and propping up the head to read [7]. In addition, long thoracic nerve palsy may be due to direct mechanical pressure by an inflamed and enlarged subcoracoid or subscapular bursa along the pathway of the nerve [58]. Long thoracic nerve injury may also be iatrogenic as consequence of chiropractic manipulation [26], the use of a single axillary crutch [59], mastectomies with axillary node dissection [1, 25], scalenotomies [1], surgical treatment of spontaneous pneumothorax [1], and post-general anesthesia for various clinical reasons $[1,2]$. Electrical shock may also cause long thoracic nerve palsy [40].

Although the association between serratus anterior paralysis and trauma is well established, there is no consensus of exactly how trauma injures the long thoracic nerve. Initial hypotheses were linked to the observation that the fifth and sixth cervical branches of the long thoracic nerve pass through the substance of the scalenus medius muscle, suggesting that spasms of this muscle could block conduction through the long thoracic nerve [32]. This hypothesis is unlikely, though, as the nerve to the unaffected rhomboids also passes through the scalenus medius muscle and the seventh cervical branch passes anterior to the muscle, bypassing the proposed causative spasm $[4,9$, 11]. Later, Gregg et al. [4] purposed a traction injury to the long thoracic nerve, showing in a cadaver study that they could double the length of the nerve by rotating, flexing, and tilting the head laterally away from the involved shoulder and then raising the ipsilateral arm overhead. They hypothesized that sudden or recurrent irritating traction force may cause serratus anterior paralysis. Foo and Swan [11] were not convinced, though, citing that since the nerve is long, it must be capable of a reasonable amount of stretch, supported by the fact that traction injuries to the brachial plexus are not always accompanied by long thoracic nerve injury. Gozna and Harris [9] showed in their cadaver study that a forceful downward pull on the arm could pinch the nerve between the second rib and the scapula and concluded this to be the site of traumatic palsy of the serratus anterior. However, there is evidence that under such extreme force, damage to the long thoracic nerve should be accompanied by damage to the brachial plexus and axillary vessels as well [4]. More recent work on cadavers suggests that injury may take place as the nerve exits the fascial sheath that encompasses it, either in the form of a traction injury [46] or in a "bow-stringing" effect [45].

\section{Trapezius palsy}

Paralysis to the trapezius muscle, like serratus anterior paralysis, is primarily neurogenic, but from injuries to the spinal accessory nerve. The superficial course of the nerve makes it susceptible to closed traction lesions in assault cases [16], motor vehicle accidents [12, 15], and direct trauma to the posterior cervical region [15]. Other direct traumas to the spinal accessory nerve include heavy lifting [14, 60], biting to the posterior cervical triangle [10], penetrating wounds to the area $[14,17,19]$, and other forms of blunt trauma to the posterior cervical triangle [12, 14, 15]. By far, the most common cause of spinal accessory nerve palsy is iatrogenic, primarily sustained during surgeries for cervical lymph node biopsy [14, 16, $19,27]$ and cervical mass excision [12, 14-16, 24, 27]. In a series of 83 consecutive patients with accessory nerve injury, Donner and Kline [14] reported $71 \%$ of cases to be iatrogenic and $24 \%$ of cases to be trauma related. In a similar study, Williams et al. [16] reported $58 \%$ of 43 patients with accessory nerve injury to be iatrogenic. Spontaneous or idiopathic trapezius paralysis has also been reported [7, 27]. 
Rhomboid palsy

Similarly, rhomboid paralysis tends to be primarily neurogenic in nature, involving the dorsal scapular nerve. An entrapment injury is the most common cause of injury reported in the literature [22, 39, 48, 49], although the site of entrapment is not well known. Unlike the long thoracic nerve, there is some strong evidence that the dorsal scapular nerve can become entrapped in the scalenus medius muscle as some have suggested [22, 48, 49]. Desong et al. [49] reported very high rates of symptom resolution after decompressing the dorsal scapular nerve by transecting the scalenus anterior and medius muscles and suggested that dorsal scapular entrapment is simply an atypical presentation of thoracic outlet syndrome. Similar findings have not been reported elsewhere. Ravindran et al. [39] reported an unusual case of suprascapular and dorsal scapular nerve entrapment in two siblings, both of whom were competitive volleyball players who developed identical symptoms in their dominant shoulder. There were six other siblings who did not play volleyball and did not have the condition, leading Ravindran et al. to suggest a familial anatomical peculiarity predisposing toward nerve entrapment. However, no site of entrapment was suggested.

In addition to entrapment syndromes, direct injury to the nerve has been reported to cause rhomboid paralysis. Saeed et al. [5] reported a case of an individual who developed shoulder pain and weakness several days after a motor vehicle accident, most likely due to a severe C5 root lesion or avulsion. In addition, anterior shoulder dislocation can also cause direct injury to the dorsal scapular nerve, as reported in a Judo player who developed extreme instability of the glenohumeral joint, resulting in six dislocations in 2 weeks [21]. A C5 radiculopathy has also been suggested as a causative factor [34]. Finally, muscle injury during overhead athletics has been implicated as well, as the deceleration of the scapula during the followthrough motion of a pitcher or volleyball player can strain and injure the rhomboids [20].

\section{Other etiologies}

Although primarily due to serratus anterior palsy, and less frequently trapezius and rhomboid palsy, these are not the only conditions that present with scapular winging. Rhomboid and trapezius muscle rupture [61] and other direct injuries to scapulothoracic muscles [62] can also cause scapular winging. Structural abnormalities can also present similarly and include rotator cuff pathology, shoulder instability, mal-united acromial fractures, aseptic necrosis of the humeral head, fibrotic shortening of the middle and posterior deltoid, and acromegalic arthropathy of the shoulder [4, 5, 62].

\section{Clinical picture and diagnosis}

\section{History}

Purported by Wiater and Bigliani [7] and Wiater and Flatow [8], the physician evaluation should include a detailed history including questions regarding hand dominance, occupation, hobbies, and current and previous level of function, answers to which will dictate the use of conservative or surgical treatment. In cases of traumatic etiology, the exact mechanism of injury should be elucidated, along with a history of surgery of the neck, shoulder, thorax, or axilla, and recent illness and immunizations [7, 8]. Key features of the physical exam relating to winging due to serratus anterior, trapezius, or rhomboid palsy is outlined in Table 1.

\section{Serratus anterior palsy}

The typical patient suffering from serratus anterior palsy will present with pain around the affected shoulder (usually the right side), which either arises spontaneously or linked to some traumatic event [4, 11]. This pain may radiate down the arm and to the scapula [3]. Pain in the shoulder is usually localized to the rhomboid and levator scapulae muscles due to spasm secondary to unopposed contraction in the absence of serratus anterior tone [8]. In addition, patients will typically complain of shoulder weakness [8], while athletes may complain of reduced performance [4]. Severe pain should raise suspicion of a neuritis, such as Parsonage-Turner syndrome [8]. In one series of 14 patients with traumatic lesions, pain was localized to the lower pole of the scapula immediately after injury and was described as having a burning quality [9]. The authors of that study consider this to be a strong diagnostic clue and advocate asking all patients with shoulder weakness after sustaining an injury specifically if they have such a burning pain. Typically, the pain usually resolves spontaneously over the next several weeks, but the patient is left with a winged scapula that is noticed by others or is occasionally felt while sitting in a chair [4, 11].

Upon physical examination, classical or medial scapular winging is usually evident at rest, with the medial and inferior borders closer to the spine and lifted superiorly when compared to the normal side [4, 63]. Scapular winging can be accentuated when the patient is asked to forward flex his arms to the horizontal (Fig. 3) and/or push on a wall in a push-up motion [4, 8, 63]. In this position, the vertebral border of the scapula lifts further from the thoracic wall due 


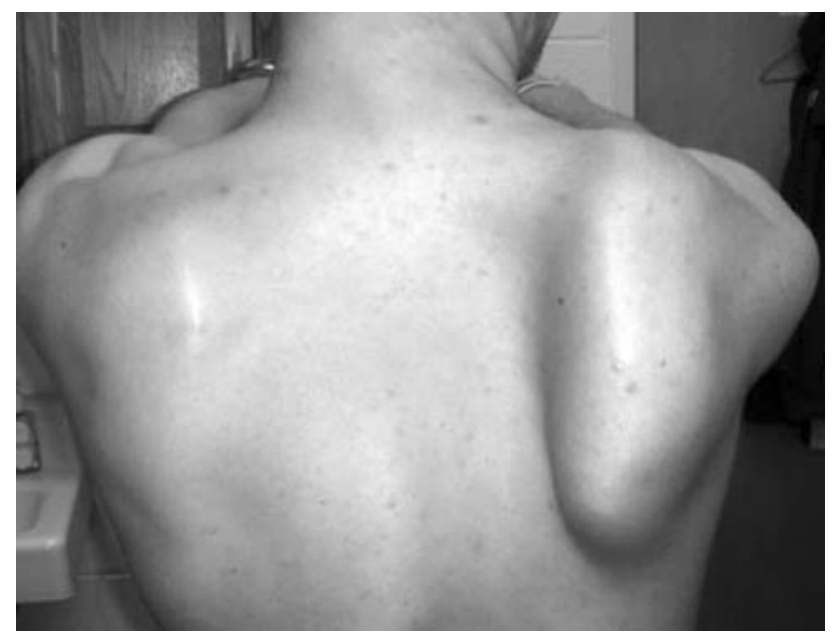

Fig. 3 Winging of the right scapula due to serratus anterior palsy, accentuated by active flexion of the arms. In addition to the medial border lifting off the posterior thoracic wall, note the medial and superior translation of the right scapula when compared to the normal left side [83, Fig. A]

to the loss of serratus anterior scapular protraction. Gregg et al. [4] point out that prominent scapular winging may not be evident until several weeks after an acute lesion in order for the trapezius to stretch out far enough. In addition, because the scapula cannot be stabilized against the thorax, forward flexion of the arm past the horizontal may be limited or impossible $[4,8,63]$. In a series of 14 patients suffering from painful scapular winging, Warner and Navarro [63] found that none of the patients could flex their shoulder above $120^{\circ}$, with an average forward flexion of $97^{\circ}$. Gregg et al. [4] found that patients with complete serratus anterior paralysis could not abduct their arms beyond $110^{\circ}$. Reproducibly, manual stabilization of the scapula against the thorax by the physician can alleviate shoulder discomfort and can allow for shoulder flexion above $150^{\circ}$ [63].

As summarized nicely by Wiater and Flatow [8], more common diseases may mimic serratus anterior palsy and lead to initial misdiagnosis. They cite examples of rotator cuff tear, fracture malunion, trapezius palsy, glenohumeral instability, impingement, acromioclavicular joint disease, biceps tendonitis, neurologic disorders, suprascapular nerve entrapment, scoliosis, and scapular osteochondroma. In previous reports, such misdiagnoses have led to 17 surgical procedures to be performed on five patients without improvement of symptoms [63] and a diagnostic delay in 10 of 14 patients [9].

\section{Trapezius palsy}

Typical presentation includes stiffness, pain, and weakness of the shoulder girdle, especially with overhead activity and upon prolonged exertion [7, 15]. Pain can be quite debilitating and can be the result of the strain and spasm of overcompensating periscapular muscles [7, 12, 15]. Patients may complain of a dull ache and heaviness around the shoulder [12, 15] and may describe the feeling as having a brick on the shoulder [15]. Trapezius paralysis and subsequent deficient rotation of the scapula may also cause pain associated with subacromioclavicular impingement $[7,12,15]$. Consistently, patients are limited in all overhead activities [7, 12, 15].

Physical examination elicits an asymmetrical neckline with drooping of the effected shoulder. This may be accompanied with lateral displacement and winging of the scapula $[12,15,16]$. Typically, winging is minimal and is accentuated during arm abduction, with the scapula moving upwards with the superior angle more lateral to the midline than the inferior angle [5]. Winging may disappear during forward flexion of the arm due to the action of the serratus anterior muscle [5]. Difficulty in abducting the arm is a consistent finding, and in one series of patients, the majority could only abduct to $80-90^{\circ}$ [16]. Chan et al. [64] suggest an additional test for accessory nerve palsy, requiring the patient to externally rotate the shoulder against a force provided by the examiner's hand. Any medial winging of the scapula is indicative of accessory nerve palsy (Fig. 4).

Identification of trapezius palsy is not straight forward, and like serratus anterior paralysis, is easily misdiagnosed. Wiater and Bigliani [7] summarize conditions with signs and symptoms that are similar to trapezius palsy and include paralysis of the rhomboid and serratus anterior muscles, herniated nucleus pulposus, scoliosis, progressive neuromuscular disease, scapular osteochondroma, fracture mal-union, stroke, herpes zoster infection, and

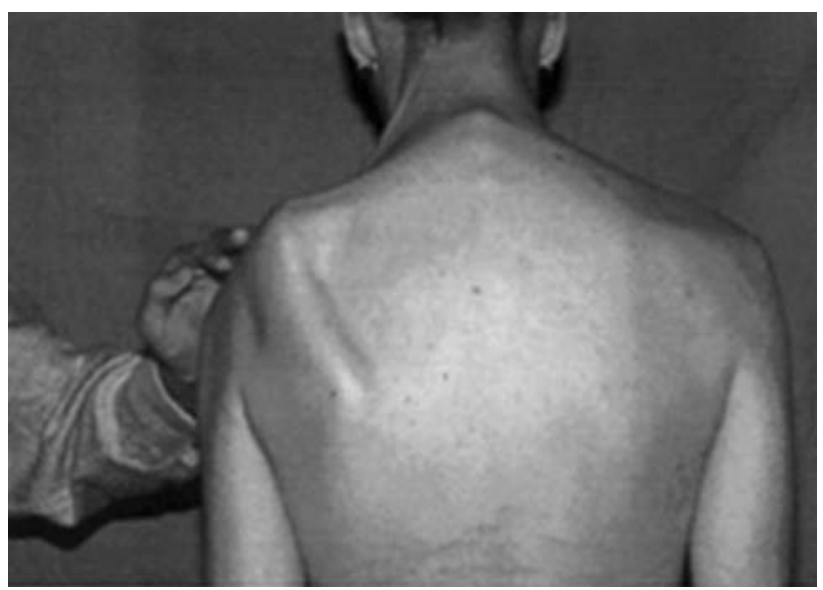

Fig. 4 A patient with pronounced winging of the left scapula during active external rotation against resistance, typical of trapezius palsy. Note the lateral displacement of the scapula with the superior angle more lateral to the midline than the inferior angle [64, Fig. 4A] 
glenohumeral instability. Other misdiagnoses include thoracic outlet syndrome, subacromial impingement, and pain about the shoulder [15].

\section{Rhomboid palsy}

The typical patient will present with pain down the medial aspect of the scapula [5, 34, 65], with pain sometimes radiating down the arm to the C5 and C6 dermatomes [48, $49,65]$. The patient may also suggest a feeling of abnormal shoulder motion [22] or traction [49] when raising the effected arm. In the only published cohort of patients with dorsal scapular nerve palsy, Desong et al. [49] reported discomfort of the neck, back, and shoulder to be the main complaint of 36 patients. In addition, neck pain was often aggravated by changes in the weather, and insomnia was common due to shoulder discomfort [49]. Symptoms were unilateral in 34 of 36 patients, and there was a preponderance of females, 28 in all [49].

Upon examination, rhomboid palsy produces a very subtle winging of the scapula, with the scapula laterally translated and the inferior angle rotated laterally [5, 34, 38]. Winging may be accentuated by having the patient extend his or her arm from a fully flexed position, during which the inferior angle of the scapula is pulled laterally and dorsally off the thoracic wall [5, 34]. If allowed to progress, atrophy of the rhomboids may be evident $[5,21$, 39]. Weakness of the rhomboids can be tested by having the patient try to bring his or her scapulas together medially [22], or by having the patient push his or her elbows backwards against resistance with hands on hips [34, 47]. Difficulty with either task suggests weakness of the rhomboids, but this may be masked by trapezius hypertrophy [21].

Due to the rhomboids anatomical position deep to the trapezius muscle and the subtleness of the scapular winging, rhomboid paralysis is a difficult diagnosis. In the cohort of Desong et al. [49], 25 out of 36 patients were initially misdiagnosed with conditions such as neurosis, over-stressed trapezius, cervical spondylosis, and shoulder periarthritis. This difficulty has led some authors to suggest dorsal scapular nerve palsy to be an under-diagnosed cause of shoulder pain [22, 50, 65].

\section{Diagnostic tests}

Currently, electromyographic testing is the only definitive diagnostic test for serratus anterior, trapezius, and rhomboid muscle paralysis, and is essential for determining which muscle is involved and to what degree of denervation [29, 35, 37, 66]. Electromyographic testing typically shows resting denervation potentials, decreased motor unit recruitment and polyphasic motor unit potentials during volitional activity $[4,5,13,21,22,26,28,29,34,35,37$, $39,40,42,43,48,53,59,65,66]$. Although diagnostically helpful in determining muscle involvement and detecting improvement and reinnervation, the initial degree of denervation cannot be used to predict the extent of recovery [28, 66]. Improvement over time on serial electromyographic examination may [35] or may not [66] correlate with clinical outcome. Nerve conduction studies of the long thoracic nerve may also be helpful in determining the severity of the lesion $[30,67]$.

Plain radiographs of the neck, chest, shoulder, and thoracic inlet are rarely diagnostic, but should be obtained to rule out structural abnormalities such as mal-united or greenstick fractures $[7,8,11,61,68]$. Computed tomography (CT) and magnetic resonant imaging (MRI) are rarely needed, but may be useful to rule out other diagnoses, such as neurofibromatous-related injury [37], disk disease and radiculopathy [52], and mass lesions [7, 8].

\section{Treatment}

\section{Serratus anterior palsy}

Isolated serratus anterior palsy responds well to conservative treatment, with most cases functionally resolving within 1-24 months $[3,4,9,11,13,24,25,28,35,57,63$, 69]. Mild deficits in endurance functioning and asymptomatic scapular winging may persist after functional recovery $[4,11]$. Patients may also learn to compensate for persistent serratus anterior paralysis by using the trapezius muscle [28]. Paralysis as a result of trauma tends to lead to a poorer prognosis $[1,4,28,66]$. To allow time for spontaneous recovery, several authors have advocated the use of conservative treatment for the first 6-24 months after symptoms begin. If adequate recovery has not been made by then, paralysis can be considered permanent and patients become candidates for corrective surgery $[4,11]$. Upon diagnosis, patients should be advised to avoid overhead use of the effected extremity and to avoid activities that cause pain $[4,28,63,69,70]$. Range of motion (ROM) exercises in the supine position should also be prescribed. In the supine position, the weight of the body prevents winging by compressing the scapula against the thorax and allows for full shoulder range of motion [3, 25, 28]. Special consideration should be taken not to stretch the serratus anterior muscle, as stretching the denervated muscle can impair the time to and extent of functional recovery [3, 28]. A scapular brace (Fig. 5) may accomplish both tasks of keeping the scapula placed against the thorax and preventing stretching of the serratus anterior muscle, and has 


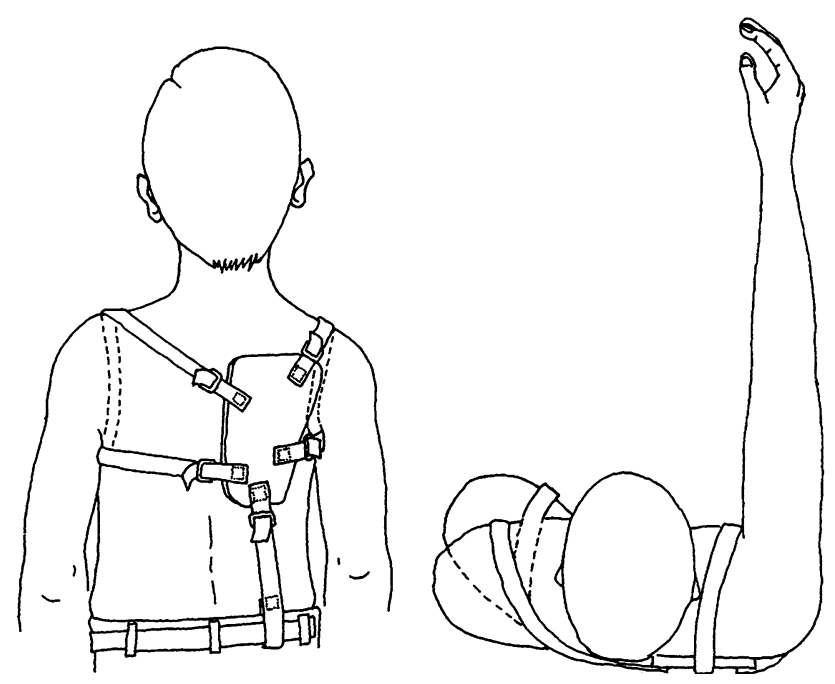

Fig. 5 A treatment option for scapular winging due to serratus anterior or trapezius muscle paralysis, the winger's brace is designed to manually press the scapula against the posterior thoracic wall, preventing stretching of the paralyzed muscle and providing limited functional recovery [71, Figs. 1 and 2]

been shown to be a generally effective treatment option for compliant individuals $[3,63,71]$. However, the brace tends to be poorly tolerated leading to poor compliance and less functional recovery [37, 63, 69, 72]. In addition, Goodman et al. [28] advocate the use of a restraint that limits abduction of the arm to only $30^{\circ}$, forcefully preventing overuse of the serratus anterior.

Watson and Schenkman [70] have identified three stages of long thoracic nerve injury and appropriate treatment at each stage. In the acute stage, denervation of the serratus anterior causes pain, and goals of treatment include pain reduction and ROM exercise. Activity modification of the patient is also important to limit further injury to the shoulder. In the intermediate stage, the pain has subsided and the nerve is beginning to heal. To maintain full ROM, passive stretching of the rhomboids, levator scapulae, and pectoralis minor is used to prevent contracture of these muscles due to the loss of serratus anterior activity. In the third or late stage, the serratus anterior becomes progressively stronger and shoulder mechanics improve. To improve strength and overhead work, strengthening exercise of all shoulder girdle muscles, including the trapezius, should be implemented and avoidance of overstretching the serratus anterior should be continued.

Serratus anterior paralysis and scapular winging will persist in approximately $25 \%$ of patients treated conservatively and such patients are candidates for surgical reconstruction [6]. Summarized by Wiater and Flatow [8], the surgical procedures to correct scapular winging fall within three categories. The first category, scapulothoracic fusion, eliminates scapular winging, but often results in loss of total elevation, pseudarthrosis, and pulmonary complications [8, 54-56, 73]. As such, it is generally considered a salvage operation after failure of other surgical procedures $[8,73]$, or reserved for patients with generalized shoulder weakness such as facioscapulohumeral dystrophy $[54,55,74]$. The second category, static stabilization, uses a fascial graft or sling to tether the scapula to the ribs or vertebral spinous processes. However, this procedure has fallen out of favor due to the recurrence of scapular winging as the fascial grafts stretch out with time [8]. The third and most popular procedure is a dynamic muscle transfer in which the sternal head of the pectoralis major is transferred to the inferior angle of the scapula extended or reinforced by a fascial auto graft $[6,8$, $9,40,41,63,69,75]$. This procedure has shown consistently positive results with improved function, resolution of winging, and relief of pain. Transfer of the pectoralis major may not be recommended for individuals looking to return to strenuous labor or contact sports, as these activities, along with lifting greater than 20 pounds, should be avoided a minimum of 6-12 months post-operatively [63, 69, 75]. Recently, surgical neurolysis or nerve transfer to the long thoracic nerve has shown early promising results, with patients expressing near complete relief of pre-operative symptoms [18, 76, 77]. As such, initial nerve exploration may be a favorable option before a muscle transfer is performed.

\section{Trapezius palsy}

In contrast to the serratus anterior, functional recovery of the trapezius muscle due to spinal accessory nerve injury does not consistently benefit from conservative management $[7,10,12,14-16,78]$. In one series of conservatively treated patients, only pain from frozen shoulder syndrome was relieved by an exercise program, while pain from muscle spasm, radiculitis, impingement, and asymmetry of the neckline persisted [12]. Conservative treatments known to have failed include physical therapy, transcutaneous nerve stimulation, external support, chiropracty, NSAIDS, and narcotic analgesics $[12,15]$. Several authors propose conservative treatment of neuropraxic lesions to the spinal accessory nerve for a minimum of 1 year [7, 37]. If inadequate functional recovery is seen at this time, additional conservative treatment is unlikely to be beneficial and surgery is indicated [7, 37]. Failure of conservative treatment is largely due to the inability of physical therapy to adequately strengthen adjacent muscle groups enough to compensate for the cross-sectional area and direction of pull of the trapezius [7, 12, 15]. A shoulder orthosis (Fig. 5) has been developed for trapezius muscle paralysis and has been used somewhat successfully in radical neck 
dissection patients [78]. Within 3 months of using the orthosis, $72 \%$ of patients were pain free, had improved shoulder girdle muscle function, and increased endurance and function due to loss of pain [78]. However, active abduction only improved by $5-20^{\circ}[78]$.

Surgical exploration and nerve repair, such as neurolysis, end-to-end suturing, or nerve grafting, has produced variable outcomes, but appear to be generally beneficial [14-17, 19, 60, 79-82]. In the largest series of 111 surgical repairs of the spinal accessory nerve, neurolysis resulted in mostly excellent results, while end-to-end suture repair resulted in slightly better outcomes than graft repair [19]. Modest recovery was seen after neurotization and dismal prognoses were seen after nerve burial into the muscle [19]. Although recovery was the norm, persistent winging of the scapula and lack of full abduction was common, as was an asymmetrical neckline with a drooping shoulder on the affected side [19]. In a recent review of the literature, authors have reported good or excellent results in approximately two-thirds of patients treated with nerve surgery [27].

The preferred method of treatment for healthy and active patients with isolated chronic trapezius palsy secondary to spinal accessory nerve injury is the Eden-Lange muscle transfer procedure $[7,12,15,80]$. A dynamic muscle transfer, the procedure involves the lateral transfer of the insertion sites of the levator scapulae and rhomboid muscles along the scapula. This maneuver redirects the force vectors of these muscles and allows them to stabilize the scapula and support the shoulder girdle, substituting the denervated trapezius $[7,12,15,80]$. The Eden-Lange surgery results in mostly good to excellent outcomes, with adequate relief of pain and functional overhead movement $[7,12,15,80]$. However, there are some limitations. Teboul et al. [27] report two predictive factors of poor outcome, including patient age over 50 years and a spinal accessory nerve lesion caused by radical neck dissection, penetrating injury, or spontaneous palsy. Romero and Gerber [80] reported poorer outcomes in the presence of an additional serratus anterior palsy or weak rhomboid muscle. In such a case, scapulothoracic fusion may be the preferred surgical procedure [7]. Some authors recommend the Eden-Lange procedure only in the case of spontaneous palsy of the trapezius, failed nerve repair, or a duration of 12-20 months have elapsed post-injury [7, 27].

\section{Rhomboid palsy}

Injury to the dorsal scapular nerve or the rhomboid muscles is usually treated conservatively with cervical spine stabilization (collar or cervical traction), muscle relaxants, anti-inflammatories, and physical therapy $[20,22,34,48$,
49, 65]. Strengthening of the trapezius is the primary objective of physical therapy, as the middle portion of the trapezius can compensate for rhomboid weakness or paralysis [34]. Local steroid block for muscle tenderness may also be useful for a minority of patients. Desong et al. [49] treated 18 patients with local steroid injection for neck tenderness. Of these, the symptoms of 6 patients were relieved, 4 managed some relief but became refractory to treatment, while 8 patients experienced no treatment effect at all. In cases of muscle strain, such as after an athletic injury, massage is an effective treatment [20].

Surgical procedures may be warranted in severe cases that are unresponsive to conservative treatment. One option is a fascial sling operation where two fascia lata grafts are used to connect the lower medial border of the scapula to the spinal muscles and the inferior angle of the scapula to the latissimus dorsi $[33,34]$. This anchors the scapula to the posterior thoracic wall, eliminating winging. However, there is concern that the fascia lata grafts may stretch or fail with time [34]. Another option is neurolysis or decompression, a procedure most authors suggest to be used only as a last resort [22, 48, 65]. Desong et al. [49] reported effective relief of symptoms for 14 out of 22 patients up to 1.5 years after undergoing decompression surgery in the anterior neck. Another three patients who had undergone the surgery were able to control their symptoms with periodic local lidocaine blocks [49]. Desong et al. advocate weekly local lidocaine blocks for 4-6 weeks after diagnosis, after which if the patient's symptoms are unresponsive, decompression surgery is warranted.

\section{Conclusions}

Although rare, scapular winging is a debilitating condition that limits functional activity of the upper extremity. Scapular winging is diagnosed easily by visible inspection of the scapula, but its etiology is often more illusive. Medial winging due to serratus anterior paralysis is accentuated when patients are asked to forward flex their arms to the horizontal and push on a wall in a push-up motion. In contrast, trapezius paralysis results in exaggerated lateral winging upon active abduction. The lateral winging of rhomboid paralysis is subtle, but may be accentuated by extending the arm from the fully flexed position. Electromyographical testing of all scapulothoracic muscles is essential for correct diagnosis. Scapular winging should initially be treated conservatively, allowing time for spontaneous recovery. Early spinal accessory nerve exploration is warranted in cases of trapezius paralysis, while decompression of the dorsal scapular nerve may be advisable after conservative treatment has failed. Serratus anterior paralysis should be treated conservatively for 
a minimum of 6 months, but preferably up to 24 months, after which further recovery through conservative treatment is unlikely. Exercises to maintain ROM is important to limit contracture of periscapular muscles, but special care must be taken not to stretch the paralyzed muscle. Strengthening exercises should be incorporated gradually and only after reinnervation of the muscle is evident. Chronic scapular winging due to serratus anterior and trapezius muscle palsies respond well to dynamic muscle transfer which leads to mostly good to excellent resolution of winging and recovery of scapulothoracic rhythm.

\section{References}

1. Kauppila LI, Vastamaki M. Iatrogenic serratus anterior paralysis. Long-term outcome in 26 patients. Chest 1996;109:31-4.

2. Martin JT. Postoperative isolated dysfunction of the long thoracic nerve: a rare entity of uncertain etiology. Anesth Analg 1989;69:614-9.

3. Johnson JT, Kendall HO. Isolated paralysis of the serratus anterior muscle. J Bone Joint Surg 1955;37:567-74.

4. Gregg JR, Labosky D, Harty M, Lotke P, Ecker M, DiStefano V, Das M. Serratus anterior paralysis in the young athlete. J Bone Joint Surg 1979;61:825-32.

5. Saeed MA, Gatens PF, Singh SS. Winging of the scapula. Am Fam Physician 1981;24:130-43.

6. Fery A. Results of treatment of anterior serratus paralysis. In: Post M, Morrey BF, Hawkins RJ, editors. Surgery of the shoulder. St. Louis: Mosby Year Book;1990. p. 325-9.

7. Wiater JM, Bigliani LU. Spinal accessory nerve injury. Clin Orthop Relat Res 1999;368:5-16.

8. Wiater JM, Flatow EL. Long thoracic nerve injury. Clin Orthop Relat Res 1999;368:17-27.

9. Gozna ER, Harris WR. Traumatic winging of the scapula. J Bone Joint Surg 1979;61:1230-3.

10. Paljarvi L, Partanen J. Biting palsy of the accessory nerve. J Neurol Neurosurg Psychiatry 1980;43:744-6.

11. Foo CL, Swann M. Isolated paralysis of the serratus anterior: a report of 20 cases. J Bone Joint Surg 1983;65:552-6.

12. Bigliani LU, Perez-Sanz JR, Wolfe IN. Treatment of trapezius palsy. J Bone Joint Surg 1985;67:871-7.

13. Schultz JS, Leonard JA. Long thoracic neuropathy from athletic activity. Arch Phys Med Rehabil 1992;73:87-90.

14. Donner TR, Kline DG. Extracranial spinal accessory nerve injury. Neurosurgery 1993;32:907-11.

15. Bigliani JU, Compito CA, Duralde XA, Wolfe IN. Transfer of the levator scapulae, rhomboid major, and rhomboid minor for paralysis of the trapezius. J Bone Joint Surg 1996;78:1534-40.

16. Williams WW, Donell ST, Twymann RS, Birch R. The posterior triangle and the painful shoulder. Ann R Coll Surg Engl 1996;78:521-5.

17. Vandeweyer E, Goldschmidt D, de Fontaine S. Traumatic spinal accessory nerve palsy. J Reconstr Microsurg 1998;14:259-61.

18. Tomaino MM. Neurophysiologic and clinical outcome following medial pectoral to long thoracic nerve transfer for scapular winging: a case report. Mircosurgery 2002;22:254-7.

19. Kim DH, Cho YJ, Tiel RL, Kline DG. Surgical outcome of 111 spinal accessory nerve injuries. Neurosurgery 2003;53:1106-13.

20. Balcom WB, Pappas AM. Musculotendinous sport injuries of the shoulder. In: Pappas AM, editor. Upper extremity injuries in the athlete. New York: Churchill Livingstone Inc; 1995. p. 229.
21. Jerosch J, Castro WHM, Geske B. Damage of the long thoracic nerve and dorsal scapular nerve after traumatic shoulder dislocation: case report and review of the literature. Acta Orthop Belg 1990;56:625-7.

22. Pecina MM, Krmpotic-Nemanie J, Markiewitz AD. Tunnel syndrome: peripheral nerve compression syndromes, 2nd ed. Boca Raton: CRC Press Inc; 1997. p. 59-61.

23. Wood VE, Frykman GK. Winging of the scapula as a complication of first rib resection. Clin Orthop Relat Res 1980;149:160 63.

24. Olarte M, Adams D. Accessory nerve palsy. J Neurol Neurosurg Psychiatry 1977;40:1113-6.

25. Duncan MA, Lotze MT, Gerber LH, Rosenberg SA. Incidence. Recovery, and management of serratus anterior palsy after axillary node dissection. Phys Ther 1983;63:1243-7.

26. Oware A, Herskovitz S, Berger AR. Long thoracic nerve palsy following cervical chiropractic manipulation. Muscle Nerve 1995; 18:1351.

27. Teboul F, Bizot P, Kakkar R, Sedel L. Surgical management of trapezius palsy. J Bone Joint Surg 2004;86:1884-90.

28. Goodman CE, Kenrick MM, Blum MV. Long thoracic nerve palsy: a follow-up study. Arch Phys Med Rehabil 1975;56:352-5.

29. Fardin P, Negrin P, Dainese R. The isolate paralysis of the serratus anterior muscle: clinical and electromyographical follow-up of 10 cases. Electromyogr Clin Neurophysiol 1978;18:379-86.

30. Petrera JE, Trojaborg W. Conduction studies of the long thoracic nerve in serratus anterior palsy of different etiology. Neurology 1984:34:1033-7.

31. Overpeck DO, Ghormley RK. Paralysis of the serratus magnus muscle caused by lesion of the long thoracic nerve. JAMA 1940;114:1994-6.

32. Remak: Cited in Gregg JR, Labosky D, Harty M, Lotke P, Ecker M, DiStefano V, Das M. Serratus anterior paralysis in the young athlete. J Bone Joint Surg 1979;61:825-32.

33. Herndon JH. Surgical reconstruction of the upper extremity. Stamford: Appleton and Lange; 1999. p. 239-40.

34. Kuhn JE. Scapulothoracic articulation: anatomy, biomechanics, pathophysiology, management. In: Iannott JP, Williams GR, editors. Disorders of the shoulder: diagnosis and management. Philadelphia: Lippincott Williams \& Wilkins; 1999. p. 824-5.

35. Kaplan PE. Electrodiagnostic confirmation of long thoracic nerve palsy. J Neurol Neurosurg Psychiatry 1980;43:50-2.

36. White SM, Witten CM. Long thoracic nerve palsy in a professional ballet dancer. Am J Sports Med 1993;21:6326-628.

37. van Tuijl JH, Schmid A, van Kranen-Mastenbroek V, Faber CG, Vles J. Isolated spinal accessory neuropathy in an adolescent: a case study. Eur J Paediatr Neurol 2006;10:83-5.

38. Akuthota V, Chou JH, Drake DF, Nadler SF, Toledo SD. Sports and performing arts medicine. 2. Shoulder and elbow overuse injuries in sports. Arch Phys Med Rehabil 2004;85(3 suppl 1):S52-8

39. Ravindran M. Two cases of suprascapular neuropathy in a family. Br J Sports Med 2003;37:539-41.

40. Marmor L, Bechtol CO. Paralysis of the serratus anterior due to electric shock relieved by transplantation of the pectoralis major muscle: a case report. J Bone Joint Surg 1963;45:156-60.

41. Iceton J, Harris WR. Treatment of winged scapula by pectoralis major transfer. J Bone Joint Surg 1987;69:108-10.

42. Elders L, Van der Meche F, Burdorf A. Serratis anterior paralysis as an occupational injury in scaffolders: two case reports. Am J Ind Med 2001;40:710-3.

43. Oakes MJ. An isolated long thoracic nerve injury in a navy airman. Mil Med 2004;169:713-5.

44. Drake RL, Vogl W, Mitchell AWM. Gray's anatomy for students. Philadelphia: Elsevier Inc; 2005. p. 633-47. 
45. Hester P, Caborn D, Nyland J. Cause of long thoracic nerve palsy: a possible dynamic fascial sling cause. J Shoulder Elbow Surg 2000;9:31-5.

46. Ebraheim NA, Lu J, Porshinsky B, Heck BE, Yeasting RA. Vulnerability of the long thoracic nerve: an anatomic study. J Shoudler Elbow Surg 1998;7:458-61.

47. McFarland EG. Examination of the shoulder: the complete guide. New York: Thieme 2006; p. 104-5.

48. Nakano KK. The entrapment neuropathies. Muscle Nerve 1978;1:264-79.

49. Desong C, Yudong G, Jie L, Liang C. Dorsal scapular nerve compression atypical thoracic outlet syndrome. Chin Med J 1995;108:582-5.

50. Tubbs RS, Tyler-Kabara EC, Aikens AC, Martin JP, Weed LL, Salter EG, Oakes WJ. Surgical anatomy of the dorsal scapular nerve. J Neurosurg 2005;102:910-11.

51. Delmonte S, Massone C, Parodi A, Rebora A. Acquired winged scapula in a patient with systemic lupus erythematous. Clin Exp Rheumatol 1998;16:82-3.

52. Makin G, Brown WF, Ebers GC. C7 radiculopathy: importance of scapular winging in clinical diagnosis. J Neurol Neurosurg Psychiatry 1986;49:640-4.

53. Phillips LH. Familial long thoracic nerve palsy: a manifestation of bracial plexus neuropathy. Neurology 1986;36:1251-3.

54. Copeland SA, Howard RC. Thoracoscapular fusion for facioscapulohumeral dystrophy. J Bone Joint Surg 1978;60:547-51.

55. Bunch WH, Siegel IM. Scapulothoracic arthrodesis in facioscapulohumeral dystrophy. J Bone Joint Surg 1993;75:372-6.

56. Hawkins RJ, Willis RB, Litchfield RB. Scapulothoracic arthrodesis for scapular winging. In: Post M, Morrey BF, Hawkins RJ, editors. Surgery of the shoulder. St. Louis: Mosby Year Book; 1990. p. 346-59.

57. Zeier FG. The treatment of winged-scapula. Clin Orthop Relat Res 1973:91:128-33.

58. Horwitz MT, Tocantins LM. An anatomical study of the role of the long thoracic nerve and the related scapular bursae in the pathogenesis of local paralysis of the serratus anterior muscle. Anat Rec 1938;71:375-85.

59. Murphy MT, Journeauz SF. Long thoracic nerve palsy after using a single axillary crutch. Clin Orthop Relat Res 2006;447:267-9.

60. Dellon AL, Campbell JN, Cornblath D. Stretch palsy of the spinal accessory nerve. J Neurosurg 1990;72:500-2.

61. Lee SG, Kim JH, Lee SY, Choi IS, Moon ES. Winged scapula caused by rhomboideus and trapezius muscles rupture associated with repetitive minor trauma. J Korean Med Sci 2006;21:581-4.

62. Lauder TD. Scapular winging. In: Frontera WR, Silver JK, editors. Frontera: essentials of physical medicine and rehabilitation, 1st ed. Hanley and Belfus 2002, Chapter 18 as published on MDConsult.com as of February 2nd, 2007.

63. Warner JJP, Navarro RA. Serratus anterior dysfunction: recognition and treatment. Clin Orthop Relat Res 1998;349:139-48.

64. Chan PKH, Hems TEJ. Clinical signs of accessory nerve palsy. J Trauma 2005;60:1142-4.
65. Fisher MA, Gorelick PB. Entrapment neuropathies: differential diagnosis and management. Postgrad Med 1985;77:160-7.

66. Friedenberg SM, Zimprich T, Harper CM. The natural history of the long thoracic and spinal accessory neuropathies. Muscle Nerve 2002;25:535-9.

67. Seror P. The long thoracic nerve conduction study revisited in 2006. Clin Neurophysiol 2006;117:2446-50.

68. Bowen TR, Miller F. Greenstick fracture of the scapula: a cause of scapular winging. J Orthop Trauma 2006;20:147-9.

69. Perlmutter GS, Leffert RD. Results of transfer of the pectoralis major tendon to treat paralysis of the serratus anterior muscle. $\mathrm{J}$ Bone Joint Surg 1999;81:377-84.

70. Watson CJ, Schenkman M. Physical therapy management of isolated serratus anterior muscle paralysis. Phys Ther 1995;75:194-202.

71. Marin R. Scapula winger's brace: a case series of the management of long thoracic nerve palsy. Arch Phys Med Rehabil 1998;79:1226-30

72. Safran MR. Nerve injury about the shoulder in athletes, part 2: long thoracic nerve, spinal accessory nerve, burners/stingers, thoracic outlet syndrome. Am J Sports Med 2004;32:1063-76.

73. Krishnan SG, Hawkins RJ, Michelotti JD, Litchfield R, Willis RB, Kim YJ. Scapulothoracic arthrodesis: indications, technique, and results. Clin Orthop Relat Res 2005;435:126-33.

74. Rhee YG, Ha JH. Long-term results of scapulothoracic arthodesis of facioscapulohumeral muscular dystrophy. J Shoulder Elbow Surg 2006;15:445-50.

75. Connor PM, Yamaguchi K, Manifold SG, Pollock RG, Flatow EL, Bigliani LU. Split pectoralis major transfer for serratus anterior palsy. Clin Orthop Relat Res 1997;341:134-42.

76. Disa JJ, Wang B, Dellon AL. Correction of scapular winging by supraclavicular neurolysis of the long thoracic nerve. J Reconstr Microsurg 2001;17:79-84.

77. Novak CB, Mackinnon SE. Surgical treatment of a long thoracic nerve palsy. Ann Thorac Surg 2002;73:1643-5.

78. Kizilay A, Kalcioglu MT, Saydem L, Ersoy Y. A new shoulder orthosis for paralysis of the trapezius muscle after radical neck dissection: a preliminary report. Eur Arch Otorrhinolaryngol 2006;263:477-80.

79. Novak CB, Mackinnon SE. Patient outcome after surgical management of an accessory nerve injury. Otolaryngol Head Neck Surg 2002;127:221-4.

80. Romero J, Gerber C. Levator scapulae and rhomboid transfer for paralysis of trapezius: The Eden-Lange procedure. J Bone Joint Surg Br 2003;85:1141-5.

81. Bertelli JA, Chizoni MF. Refinements in the technique for repair of the accessory nerve. J Hand Surg 2006;31:1401-6.

82. Okajima S, Tamai K, Fujiwara H, Kobashi H, Hirata M, Jubo T. Surgical treatment for spinal accessory nerve injury. Microsurgery $2006 ; 26: 237-77$.

83. Vinson EN. Clinical images: scapular winging. Arthritis Rheum 2006;54:4027. 